\title{
PERHITUNGAN RADIOAKTIVITAS UDARA IODINE-131 PADA KECELAKAAN DIPOSTULASIKAN 5 ELEMEN BAKAR MELELEH DENGAN VARIASI KECEPATAN ANGIN MENGGUNAKAN SOFTWARE HOTSPOT
}

\section{CALCULATION OF AIR RADIOACTIVITY OF IODINE-131 IN POST- POSTED ACCIDENTS 5 MELTED FUEL ELEMENTS WITH VARIATION OF WIND SPEEDS USING HOTSPOT SOFTWARE}

\author{
Suhartono', Nazly Kurniawan², \\ 1,2 Pusat Reaktor Serba Guna, Badan Tenaga Nuklir Nasional \\ Email: hartono s@batan.go.id
}

Diterima : 2 Oktober 2020; diperbaiki : 8 Oktober 2020; disetujui : 19 Oktober 2020

\begin{abstract}
ABSTRAK
PERHITUNGAN RADIOAKTIVITAS UDARA IODINE-131 PADA KECELAKAAN DIPOSTULASIKAN 5 ELEMEN BAKAR MELELEH DENGAN VARIASI KECEPATAN ANGIN MENGGUNAKAN SOFTWARE HOTSPOT. Pada kondisi kecelakaan yang dipostulasikan yaitu kecelakaan melebihi batas desain dengan 5 elemen bahan bakar meleleh akan mengakibatkan terlepasnya zat radioaktif ke lingkungan melalui cerobong reaktor yang menyebabkan RSGGAS dalam keadaan kedaruratan nuklir. Dalam kondisi kedaruratan nuklir diperlukan tindakan segera mungkin untuk menghindari ekskalasi yang lebih besar terhadap dampak radiasi internal pada personil disekitar RSG-GAS. Pada program kesiapsiagaan nuklir RSG-GAS telah disiapkan code untuk perhitungan radioaktivitas udara yang lepas ke lingkungan melalui cerobong. Pada tulisan ini dilakukkan perhitungan radioaktivitas I-131 di udara yang lepas kelingkungan melalai cerobong dengan program code Hotspot. Pada perhitungan ini fokus pada I-131 dikarenakan dapat memberikan dampak negative pada personil yang menerima dosis melebihi batas. Selain itu nuklida l-131 di udara yang dominan lebih cepat terlepas ke lingkungan. Perhitungan radioaktivitas udara untuk nuklida I-131 dilakukan dengan menggunakan source term nilai aktivitas nuklida l-131 dengan variasi kecepatan udara 1 $\mathrm{m} /$ detik sampai dengan $5 \mathrm{~m} /$ detik. Variasi kecepatan angin diambil berdasarkan kondisi meteorologi dan klimatologi disekitar reaktor. Kecepatan angin $1 \mathrm{~m} /$ detik jarak $15 \mathrm{Km}$ radioaktivitas nuklida $\mathrm{l}-131$ 2,30E-02 $\mathrm{Bq} / \mathrm{cm}^{3}$, kecepatan angin $2 \mathrm{~m} /$ detik jarak $25 \mathrm{Km}$ radioaktivitas nuklida $\mathrm{I}-131 \mathrm{3}, 60 \mathrm{E}-2 \mathrm{~Bq} / \mathrm{cm}^{3}$, kecepatan angin $3 \mathrm{~m} /$ detik jarak $35 \mathrm{Km}$ radioaktivitas nuklida $1-131 \quad 3,30 E-2 \quad B q / \mathrm{cm}^{3}$, kecepatan angin $4 \mathrm{~m} /$ detik jarak $45 \mathrm{Km}$ radioaktivitas nuklida $\mathrm{l}-131 \mathrm{2}, 60 \mathrm{E}-2 \mathrm{~Bq} / \mathrm{cm}^{3}$, kecepatan angin $5 \mathrm{~m} /$ detik jarak $50 \mathrm{Km}$ radioaktivitas nuklida $\mathrm{I}-1315,40 \mathrm{E}-2 \mathrm{~Bq} / \mathrm{cm}^{3}$.
\end{abstract}

Kata kunci : Radioaktivitas lodine-131, Software Hotspot, Kedaruratan nuklir

\section{ABSTRAC}

THE CALCULATION OF AIR RADIOACTIVITY OF IODINE-131 IN THE ACCIDENT POSTULATED 5 ELEMENTS OF MELTED FUEL WITH VARIATIONS IN WIND SPEED USING HOTSPOT SOFTWARE. In the postulated accident condition, an accident exceeding the design limit with 5 elements of the fuel melting will result in the release of radioactive substances into the environment through the reactor chimney causing RSG-GAS to be in a state of nuclear emergency. In a nuclear emergency, immediate action is needed to avoid a 
bigger escalation of the impact of internal radiation on personnel around RSG-GAS. The RSGGAS nuclear preparedness program has prepared a code for calculating the radioactivity of air released into the environment through the chimney. In this paper, radioactivity calculations for I131 in the air that escape the environment through the chimney are carried out using the Hotspot code program. In this calculation the focus is on I-131 because it can have a negative impact on personnel who receive doses exceeding the limit. In addition, the dominant I-131 nuclide in the air is released more quickly into the environment. The calculation of air radioactivity for nuclide I-131 was carried out using the source term of the activity value of the nuclide l-131 with a variation of air velocity from $1 \mathrm{~m} / \mathrm{sec}$ to $5 \mathrm{~m} / \mathrm{sec}$. Wind speed variations are taken based on meteorological and climatological conditions around the reactor. Wind speed $1 \mathrm{~m} /$ sec distance $15 \mathrm{Km}$ radioactivity nuclides $\mathrm{l}-1312.30 \mathrm{E}-02 \mathrm{~Bq} / \mathrm{cm} 3$, wind speed $2 \mathrm{~m}$ / sec distance $25 \mathrm{Km}$ radioactivity nuclides l-131 3.60E-2 Bq / cm3, wind speed $3 \mathrm{~m} /$ second distance $35 \mathrm{Km}$ radioactivity nuclides $\mathrm{I}-1313,30 \mathrm{E}-2 \mathrm{~Bq} / \mathrm{cm} 3$, wind speed $4 \mathrm{~m} / \mathrm{sec}$ distance 45 $\mathrm{Km}$ radioactivity nuclides I-131 2,60E-2 $\mathrm{Bq} / \mathrm{cm} 3$, wind speed $5 \mathrm{~m} / \mathrm{sec}$ distance $50 \mathrm{Km}$ radioactivity of nuclides I-131 5.40E-2 Bq / cm3.

Keyword : Radioactivity lodine-131, Sofware of Hotspot, Nuclear Emergency

\section{PENDAHULUAN}

\section{Reaktor Serba Guna G.A.}

Siwabessy merupakan reaktor riset yang dimiliki oleh Indonesia dengan daya termal maksimal yang dibangkitkan 30 MW. Reaktor ini merupakan reaktor riset yang dapat digunakan untuk berbagai penelitian antara lain uji bahan, iradiasi target, uji bahan bakar reaktor daya dan masih banyak lagi manfaatnya. Selain memberikan manfaat yang banyak terdapat resiko yang besar bila reaktor mengalami kecelakaan. Kecelakaan yang ditimbulkan dapat memberikan dampak yang besar untuk lingkungan sekitar reaktor. Upaya yang dilakukan oleh Pusat Reaktor Serba Guna sebagai pengelola Reaktor Serba Guna G.A. Siwabessy (RSG-GAS) telah menyiapkan program kesiapsiagaan nuklir untuk menanggulangi bila terjadi kedaruratan reaktor RSG-GAS ${ }^{[1]}$. Agar personil dan lingkungan yang berada disekitar reaktor aman dari bahaya radiasi dari reaktor yang mengalami kecelakaan. Pemegang Izin (PI) melakukan mitigasi untuk mencegah eskalasi bahaya radiologi, mengurangi potensi lepasan zat radioaktif atau paparan radiasi. Tindakan yang dilakukan adalah dengan melakukan perhitungan radioaktivitas udara yang keluar melalui cerobong reaktor RSGGAS. Salah satu nuklida yang dilakukan pengamatan adalah nuklida I-131. Pemilihan terhadap terhadap nuklida I131 dilakukan karena karena potensi bahaya yang ditimbulkan dapat menyebabkan kanker tiroid bila nuklida I131 terhirup oleh manusia. Perhitungan tersebut dapat dilakukan dengan simulasi menggunakan perangkat lunak HOTSPOT. Data yang diperlukan untuk simulasi perangkat lunak HOTSPOT adalah source term aktivitas nuklida I131 pada kondisi BDBA (Beyond Desain Basic Accident) dengan postulasi 5 elemen bakar reaktor meleleh yang merupakan output dari running program ORIGEN2. Banyak nuklida yang lepas ke lingkungan bila terjadi kecelakaan reaktor selain I-131 tetapi potensi bahayanya beda dengan potensi yang diakibatkan oleh I-131.

Tujuan dari simulasi adalah untuk mengetahui besarnya 
radioaktivitas udara nuklida I-131 apakah melebih batas yang ditetapkan oleh Badan Regulasi yaitu BAPETEN. Dengan perhitungan radiaoaktivitas udara nuklida I-131 sehingga dapat diketahui jarak yang aman terbebas dari kontaminan nuklida I-131. Dilakukan perhitungan dengan menggunakan software HOTSPOT karena perangkat ini cocok untuk mendukung perhitungan pada saat kondisi kedaruratan agar informasi radioaktivitas nuklida $\mathrm{I}-131 \mathrm{di}$ lingkungan sekitar RSG-GAS dengan cepat dan akurat segera diketahui.

\section{METODE}

Dalam situasi kedaruratan nuklir pada instalasi reaktor RSG-GAS tindakan yang utama adalah menyelamatkan jiwa yang berada di instalasi reaktor RSG-GAS dan yang berada disekitar reaktor RSG-GAS. Bahaya yang ditimbulkan dari kecelakaan reaktor yaitu lepasnya radioaktif kelingkungan sekitar reaktor. Besarnya aktivitas Radionuklida yang lepas dari cerobong reaktor sudah mempertimbangkan prosentasi udara yang dipermukaan kolam reaktor yang terhisap sistem ventilasi sebesar $60 \%$ dan melewati sistem ventilasi dan mengalir dengan menuju cerobong dengan laju alir udara sebesar kurang lebih $20.000 \mathrm{~m}^{3} / \mathrm{jam} .{ }^{[2]}$ Besarnya lepasan radioaktivitas udara kelingkungan sekitar reaktor G.A Siwabessy telah menerapkan aturan sesuai dengan Laporan Analisis Keselamatan (LAK) yang telah di setujui oleh BAPETEN. Sistem isolasi gedung dapat bekerja dengan sempurna bila telah melebihi batas setting yang telah ditentukan sehingga tidak terjadi lepasan zat radioaktif ke lingkungan akan tetapi bila sistem isolasi mengalami gagal maka akan terjadi lepasan radioaktivitas ke lingkungan. Demikian itu yang dikhawatirkan sehingga dilakukan perhitungan berapa besarnya lepasan radioaktivitas ke lingkungan agar tindakan yang dilakukan pada kondisi kedaruratan dapat mengurangi dampak yang membahayakan personil yang di dalam instalasi dan di lingkungan.

Kondisi kedaruratan yang terjadi di reaktor G.A. Siwabessy dengan lepasnya radioaktivitas udara ke lingkungan sekitar reaktor maka tindakan yang aman adalah memerapkan zona tindakan seperti pada Tabel 2. Dengan demikian dengan diketahui besarnya radioaktivitas udara nuklida I-131 maka penerapan tindakan pada zona tersebut lebih mudah.

Sedangkan timbulnya I-131 di dalam teras reaktor akibat dari bahan bakar yang leleh atau mengalami kerusakan. Besarnya aktivitas nuklida yang lepas dari cerobong reaktor RSGGAS dapat diketahui besarnya dengan simulasi program ORIGEN 2 dengan telah mempertimbangkan bahwa $60 \%$ udara permukaan kolam sirkulasi melalui beberapa filter dengan efisiensi ( $\eta$ ) untuk lodine $0,99 \%$ menuju cerobong dan $40 \%$ udara sirkulasi di balai operasi. Dengan memasukkan besarnya aktivitas nuklida pada software HOTSPOT dapat dihitung besarnya radioaktivitas udara yang berada di sekitar reaktor RSG-GAS. Dengan demikian tindakan yang dilakukan dengan diketahuinya radioaktivitas di udara di sekitar reaktor RSG-GAS tindakan penanggulangan kedaruratan nuklir dapat dilakukan dengan baik untuk menghindari bahaya internal terhadap personal yang berada di sekitar reaktor RSG-GAS.

Data yang diperlukan untuk input data software HOTSPOT adalah sebagai berikut :

- Data Meteorologi terbaru di sekitar RSG-GAS menggunakan data rona lingkungan yang dikeluarkan oleh 
BMKG (Kecepatan dan arah angin serta stabilitas udara) dari pengelola Kawasan Nuklir Serpong (KNS) ${ }^{[3]}$

- Data spesifikasi dimensi cerobong (tinggi cerobong dan diameter cerobong)

- Source term Aktivitas I-131 pada saat 5 elemen bakar leleh (simulasi dengan perangkat lunak ORIGEN 2). Simulasi perangkat lunak ORIGEN 2 digunakan untuk mengetahui besarnya aktivitas nuklida yang berada di teras reaktor pada saat bahan bakar leleh.

- Data laju alir udara dalam cerobong, temperatur udara luar dan temperatur udara di dalam cerobong.

Bila terjadi lepasan zat radioaktif dari cerobong reaktor maka penyebaran gas atau partikel radionuklida yang terlepas ke atmosfir dipengaruhi oleh arah dan kecepatan angin. Atmosfir umumnya mengalami turbulensi, dan material yang terlepas mengalami difusi selama penyebaran. Konsentrasi radionuklida di atmosfir dihitung dengan persamaan Gaussian model persamaan tersebut digunakan dalam perangkat lunak HotSpot Versi 3.0.3 seperti ditunjukkan pada persamaan $1 .{ }^{[4]}$

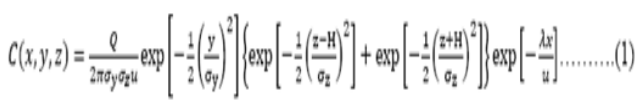

dengan:

$\mathrm{C}=$ konsentrasi radionuklida di atmosfir pada koordinat $(\mathrm{x}, \mathrm{y}, \mathrm{z}),\left(\mathrm{Ci} / \mathrm{m}^{3}\right)$

$\mathrm{Q}=$ Source term $(\mathrm{I}-131)=$ Aktivitas (hasil running ORIGEN 2)

$\lambda=$ konstanta peluruhan Radionuklida ( $\mathrm{s}^{-}$

1)

$\mathrm{H}=$ tinggi pelepasan efektif $(\mathrm{m})$

$\mathrm{x}=$ jarak downwind $(\mathrm{m})$

$y=$ jarak crosswind $(\mathrm{m})$

$\mathrm{z}=$ ketinggian sumbu vertikal $(\mathrm{m})$ $\mathrm{u}=$ kecepatan angin rata-rata pada

ketinggian lepasan ( $\mathrm{m} /$ detik)

$\mathrm{L}=$ ketinggian lapisan inversi $(\mathrm{m})$

Langkah simulasi dengan menggunakan

HOTSPOT Versi 3.0.3 sebagai berikut :

1. Menyiapkan parameter masukan perangkat lunak HOTSPOT Versi 3.0.3. Parameter yang di butuhkan seperti pada Tabel 1. 
Tabel 1. Parameter input data perangkat lunak HotSpot Versi 3.0.3

\begin{tabular}{|l|l|l|}
\hline No & \multicolumn{1}{|c|}{ Parameter } & \multicolumn{1}{c|}{ Input Data } \\
\hline 1. & $\begin{array}{l}\text { Produk fisi radio nuklida I-131 kondisi } \\
\text { BDBA yang lepas dari cerobong } \\
\text { reaktor RSG-GAS }\end{array}$ & $4,28 \times 10^{10} \mathrm{~Bq}$ (Lihat Tabel 1.) \\
\hline 2. & Tinggi cerobong & $56 \mathrm{~m}$ \\
\hline 3. & Diameter cerobong & $1,5 \mathrm{~m}$ \\
\hline 4. & Temperatur udara luar & $32^{\circ} \mathrm{C}$ \\
\hline 5. & Temperatur udara dari cerobong & $29^{\circ} \mathrm{C}$ \\
\hline 6. & Laju alir udara & $3,4 \mathrm{~m} / \mathrm{dtk}$ \\
\hline 7. & $\begin{array}{l}\text { Jarak pengukuran yang diinginkan } \\
\text { (Kilometer) }\end{array}$ & 0,$2 ; 0,3 ; 0,4 ; 0,5 ; 0,6 ; 0,7 ; 0,8 ; 0,9 ;$ \\
& & $50 ; 10 ; 15 ; 20 ; 25 ; 30 ; 35 ; 40 ; 45 ;$ \\
\hline 8. & Kecepatan angin & $1-5 \mathrm{~m} /$ detik \\
\hline 9. & Arah angin dominan & Timur \\
\hline 10. & Stabilitas udara & $\mathrm{C}($ Slightly unstable) \\
\hline
\end{tabular}

2. Parameter kecepatan angin, arah dan stabilitas udara di dapatkan dari data PPIKSN-BATAN berupa Pemutahiran Data Rona Lingkungan di KNS. Produk fisi dari cerobong reaktor G .A Siwabessy kondisi BDBA terlihat pada Tabel 2, adalah simulasi dengan menggunakan perangkat lunak ORIGEN 2.

Tabel 2. Produk fisi dari cerobong kondisi BDBA reaktor RSG-GAS ${ }^{[5]}$

\begin{tabular}{|l|l|}
\hline $\begin{array}{c}\text { Radio- } \\
\text { nuklida }\end{array}$ & $\begin{array}{c}\text { Aktivitas, } \\
\mathbf{B q}\end{array}$ \\
\hline $\mathrm{Kr}-85$ & $9.05 \mathrm{E}+12$ \\
\hline $\mathrm{Kr}-85 \mathrm{~m}$ & $7.85 \mathrm{E}+12$ \\
\hline $\mathrm{Kr}-87$ & $1.59 \mathrm{E}+15$ \\
\hline $\mathrm{Kr}-88$ & $2.24 \mathrm{E}+15$ \\
\hline $\mathrm{Xe}-133$ & $9.95 \mathrm{E}+13$ \\
\hline $\mathrm{Xe}-135$ & $7.16 \mathrm{E}+15$ \\
\hline Rb-88 & $5.73 \mathrm{E}+07$ \\
\hline Sr-89 & $9.12 \mathrm{E}+07$ \\
\hline Sr-90 & $1.79 \mathrm{E}+06$ \\
\hline Sr-91 & $9.10 \mathrm{E}+07$ \\
\hline $\mathrm{Y}-90$ & $1.93 \mathrm{E}+06$ \\
\hline Y-91 & $1.09 \mathrm{E}+08$ \\
\hline
\end{tabular}

\begin{tabular}{|l|c|}
\hline $\begin{array}{c}\text { Radio- } \\
\text { nuklida }\end{array}$ & $\begin{array}{c}\text { Aktivitas, } \\
\text { Bq }\end{array}$ \\
\hline $\mathrm{Zr}-95$ & $1.18 \mathrm{E}+08$ \\
\hline $\mathrm{Zr}-97$ & $9.22 \mathrm{E}+07$ \\
\hline $\mathrm{Nb}-95$ & $1.16 \mathrm{E}+08$ \\
\hline $\mathrm{Mo}-99$ & $9.41 \mathrm{E}+07$ \\
\hline Ru-103 & $6.00 \mathrm{E}+07$ \\
\hline Ru-106 & $1.56 \mathrm{E}+07$ \\
\hline Rh-105 & $3.60 \mathrm{E}+06$ \\
\hline $\mathrm{Te}-129$ & $1.36 \mathrm{E}+07$ \\
\hline $\mathrm{Te}-129 \mathrm{~m}$ & $1.35 \mathrm{E}+07$ \\
\hline Te-131m & $7.71 \mathrm{E}+07$ \\
\hline Te-132 & $6.70 \mathrm{E}+07$ \\
\hline Sb-125 & $2.16 \mathrm{E}+06$ \\
\hline
\end{tabular}

\begin{tabular}{|l|l|}
\hline $\begin{array}{c}\text { Radio- } \\
\text { nuklida }\end{array}$ & $\begin{array}{c}\text { Aktivitas, } \\
\text { Bq }\end{array}$ \\
\hline $\mathrm{I}-131$ & $4.28 \mathrm{E}+10$ \\
\hline $\mathrm{I}-132$ & $6.68 \mathrm{E}+10$ \\
\hline $\mathrm{I}-133$ & $1.07 \mathrm{E}+11$ \\
\hline $\mathrm{I}-134$ & $1.19 \mathrm{E}+11$ \\
\hline $\mathrm{I}-135$ & $9.95 \mathrm{E}+10$ \\
\hline $\mathrm{Zn}-65$ & $2.23 \mathrm{E}+04$ \\
\hline $\mathrm{Cs}-134$ & $4.94 \mathrm{E}+07$ \\
\hline $\mathrm{Cs}-137$ & $4.90 \mathrm{E}+07$ \\
\hline Ba-140 & $9.90 \mathrm{E}+07$ \\
\hline La-140 & $9.84 \mathrm{E}+07$ \\
\hline $\mathrm{Ce}-141$ & $1.93 \mathrm{E}+08$ \\
\hline $\mathrm{Ce}-143$ & $9.33 \mathrm{E}+07$ \\
\hline $\mathrm{Ce}-144$ & $4.96 \mathrm{E}+07$ \\
\hline
\end{tabular}


Tabel 3. Zona tindakan kedarutan ${ }^{[6]}$

\begin{tabular}{|c|c|c|}
\hline $\begin{array}{c}\text { Radius zona tindakan } \\
\text { pencegahan }\end{array}$ & $\begin{array}{c}\text { Radius zona } \\
\text { perencanaan }\end{array}$ & $\begin{array}{c}\text { Radius pengawasan bahan } \\
\text { pangan }\end{array}$ \\
\hline $\begin{array}{c}\text { Minimal dinding } \\
\text { terluar gedung reaktor }\end{array}$ & $0,5-5 \mathrm{~km}$ & $5-50 \mathrm{~km}$ \\
\hline
\end{tabular}

Tabel 4. Hasil perhitungan radioaktivitas udara nuklida I-131 pada kondisi BDBA dengan 5 variasi kecepatan angin.

\begin{tabular}{|c|c|c|c|c|c|}
\hline $\begin{array}{l}\text { Jarak } \\
(\mathrm{Km})\end{array}$ & $\begin{array}{c}\text { Radioaktivitas } \\
\text { udara untuk } \\
\text { nuklida I-131 } \\
\text { pada } \\
\text { kecepatan angin } \\
1,0 \mathrm{~m} / \mathrm{dtk} \\
\text { Stabilitas C } \\
\left(\mathrm{Bq} / \mathrm{cm}^{3}\right) \\
\end{array}$ & $\begin{array}{c}\text { Radioaktivitas } \\
\text { udara untuk } \\
\text { nuklida I-131 } \\
\text { pada } \\
\text { kecepatan angin } \\
2 \mathrm{~m} / \mathrm{dtk}) \\
\text { Stabilitas C } \\
\left(\mathrm{Bq} / \mathrm{cm}^{3}\right) \\
\end{array}$ & $\begin{array}{c}\text { Radioaktivitas } \\
\text { udara untuk } \\
\text { nuklida I-131 } \\
\text { pada } \\
\text { kecepatan } \\
\text { angin } 3 \mathrm{~m} / \mathrm{dtk}) \\
\text { Stabilitas C } \\
\left(\mathrm{Bq} / \mathrm{cm}^{3}\right)\end{array}$ & $\begin{array}{c}\text { Radioaktivitas } \\
\text { udara untuk } \\
\text { nuklida I-131 } \\
\text { pada } \\
\text { kecepatan } \\
\text { angin } 4 \mathrm{~m} / \mathrm{dtk}) \\
\text { Stabilitas C } \\
\left(\mathrm{Bq} / \mathrm{cm}^{3}\right) \\
\end{array}$ & $\begin{array}{c}\text { Radioaktivitas } \\
\text { udara untuk } \\
\text { nuklida I-131 } \\
\text { pada } \\
\text { kecepatan angin } \\
5 \mathrm{~m} / \mathrm{dtk}) \\
\text { Stabilitas C } \\
\left(\mathrm{Bq} / \mathrm{cm}^{3}\right) \\
\end{array}$ \\
\hline 0,2 & $1,50 \mathrm{E}+04$ & $8,40 \mathrm{E}+03$ & $5,80 \mathrm{E}+03$ & $4,40 \mathrm{E}+03$ & $3,50 \mathrm{E}+03$ \\
\hline 0,3 & $2,00 \mathrm{E}+05$ & $1,10 \mathrm{E}+05$ & $7,90 \mathrm{E}+04$ & $6,00 \mathrm{E}+04$ & $4,90 \mathrm{E}+04$ \\
\hline 0,4 & $3,50 \mathrm{E}+05$ & $2,10 \mathrm{E}+05$ & $1,50 \mathrm{E}+05$ & $1,10 \mathrm{E}+05$ & $9,30 \mathrm{E}+04$ \\
\hline 0,5 & $3,70 \mathrm{E}+05$ & $2,30 \mathrm{E}+05$ & $1,70 \mathrm{E}+05$ & $1,30 \mathrm{E}+05$ & $1,10 \mathrm{E}+05$ \\
\hline 0,6 & $3,30 \mathrm{E}+05$ & $2,10 \mathrm{E}+05$ & $1,60 \mathrm{E}+05$ & $1,20 \mathrm{E}+05$ & $1,00 \mathrm{E}+05$ \\
\hline 0,7 & $2,70 \mathrm{E}+05$ & $1,90 \mathrm{E}+05$ & $1,40 \mathrm{E}+05$ & $1,10 \mathrm{E}+05$ & $8,90 \mathrm{E}+04$ \\
\hline 0,8 & $2,20 \mathrm{E}+05$ & $1,60 \mathrm{E}+05$ & $1,20 \mathrm{E}+05$ & $9,30 \mathrm{E}+04$ & $7,70 \mathrm{E}+04$ \\
\hline 0,9 & $1,80 \mathrm{E}+05$ & $1,30 \mathrm{E}+05$ & $9,90 \mathrm{E}+04$ & $7,90 \mathrm{E}+04$ & $6,60 \mathrm{E}+04$ \\
\hline 1,0 & $1,40 \mathrm{E}+05$ & $1,10 \mathrm{E}+05$ & $8,40 \mathrm{E}+04$ & $6,80 \mathrm{E}+04$ & $5,70 \mathrm{E}+04$ \\
\hline 5,0 & $4,10 \mathrm{E}+02$ & $1,60 \mathrm{E}+03$ & $2,10 \mathrm{E}+03$ & $2,30 \mathrm{E}+03$ & $2,30 \mathrm{E}+03$ \\
\hline 10,0 & $2,40 \mathrm{E}+00$ & $6,80 \mathrm{E}+01$ & $1,90 \mathrm{E}+02$ & $2,80 \mathrm{E}+02$ & $3,50 \mathrm{E}+02$ \\
\hline 15,0 & $2,30 \mathrm{E}-02$ & $4,70 \mathrm{E}+00$ & $2,60 \mathrm{E}+01$ & $5,70 \mathrm{E}+01$ & $8,60 \mathrm{E}+01$ \\
\hline 20,0 & $2,60 \mathrm{E}-04$ & $3,90 \mathrm{E}-01$ & $4,40 \mathrm{E}+00$ & $1,40 \mathrm{E}+01$ & $2,50 \mathrm{E}+01$ \\
\hline 25,0 & $3,20 \mathrm{E}-06$ & $3,60 \mathrm{E}-02$ & $8,20 \mathrm{E}-01$ & $3,60 \mathrm{E}+00$ & $8,30 \mathrm{E}+00$ \\
\hline 30,0 & $4,30 \mathrm{E}-08$ & $3,50 \mathrm{E}-03$ & $1,60 \mathrm{E}-01$ & $1,00 \mathrm{E}+00$ & $2,90 \mathrm{E}+00$ \\
\hline
\end{tabular}




\begin{tabular}{lccccc}
\hline 35,0 & $5,90 \mathrm{E}-10$ & $3,50 \mathrm{E}-04$ & $3,30 \mathrm{E}-02$ & $2,90 \mathrm{E}-01$ & $1,00 \mathrm{E}+00$ \\
\hline 40,0 & $8,40 \mathrm{E}-12$ & $3,60 \mathrm{E}-05$ & $6,90 \mathrm{E}-03$ & $8,60 \mathrm{E}-02$ & $3,80 \mathrm{E}-01$ \\
\hline 45,0 & $1,20 \mathrm{E}-13$ & $3,80 \mathrm{E}-06$ & $1,50 \mathrm{E}-03$ & $2,60 \mathrm{E}-02$ & $1,40 \mathrm{E}-01$ \\
\hline 50,0 & $1,80 \mathrm{E}-15$ & $4,10 \mathrm{E}-07$ & $3,20 \mathrm{E}-04$ & $8,10 \mathrm{E}-03$ & $5,40 \mathrm{E}-02$ \\
\hline
\end{tabular}

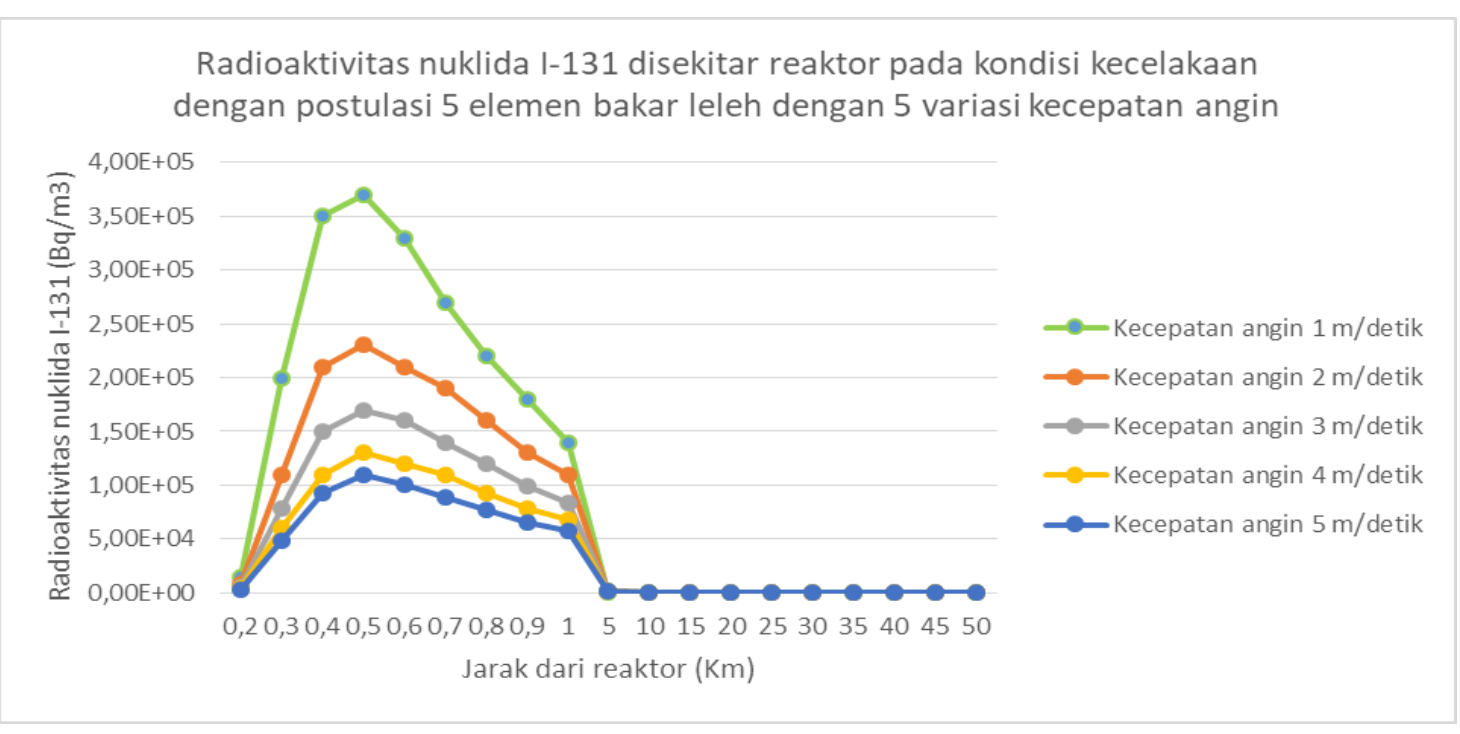

Gambar 1. Radioaktivitas nuklida I-131 dengan variasi kecepatan angin 


\section{HASIL DAN PEMBAHASAN}

Pada kondisi terjadi kedaruratan nuklir di reaktor RSG-GAS dalam program kesiapsiagaan nuklir dalam melakukan tindakan penanggulangan telah melakukan pembagian zona kedaruratan nuklir sesuai dengan Perka BAPETEN No,1 Tahun 2010 zona tersebut seperti pada Tabel 3.

Dari hasil simulasi yang dilakukan dengan menggunakan software HOTSPOT versi 3.03 didapatkan hasil radioaktivitas udara nuklida $\mathrm{I}-131$ dengan variasi kecepatan udara $1-5 \mathrm{~m} / \mathrm{s}$ seperti terlihat pada Tabel 4.

Besarnya radioaktivitas nuklida I131 disekitar reaktor RSG-GAS saat terjadi kedaruratan besarnya tergantung pada aktivitas nuklida I-131 yang keluar dari cerobong reaktor RSG-GAS dari simulasi ORIGEN 2. Besarnya radioaktivitas $\mathrm{I}-131$ yang terdisposisi pada jarak tertentu dari reaktor RSGGAS dipengaruhi oleh fungsi dari kecepatan angin, arah angin stabilitas udara dan cuaca basah atau kering. Kecepatan angin semakin kencang maka radioaktivitas udara $\mathrm{I}-131$ terdisposisi semakin jauh, semakin jauh maka radioaktivitas udara semakin kecil. Nilai batas keselamatan untuk lepasan radioaktivitas nuklida $\mathrm{I}-131$ di lingkungan adalah $2,7 \times 10^{-2} \mathrm{~Bq} / \mathrm{m}^{3}[7]$. Bila nilai batas tersebut terlewati maka dilakukan tindakan pengendalian pada daerah tersebut.

Lepasan radioaktivitas udara nuklida I-131 tertinggi dengan variasi kecepatan angin $1-5 \mathrm{~m} /$ detik adalah pada jarak 0,5 $\mathrm{km}$ dari reaktor G.A. Siwabessy adalah $3,70 \mathrm{E}+05 \mathrm{~Bq} / \mathrm{cm}^{3}, 2,30 \mathrm{E}+05 \mathrm{~Bq} / \mathrm{cm}^{3}$, $1,70 \mathrm{E}+05 \mathrm{~Bq} / \mathrm{cm}^{3}, 1,30 \mathrm{E}+05 \mathrm{~Bq} / \mathrm{cm}^{3}$ dan $1,10 \mathrm{E}+05 \mathrm{~Bq} / \mathrm{cm}^{3}$. Radioaktivitas udara nuklida I-131 mengalami penuruhan secara signifikan pada jarak $5 \mathrm{Km}$ dari reaktor G.A. Siwabessy meskipun demikian nilainya masih diatas dari batas yang dipersyaratkan oleh BAPETEN. Dari Grafik 1. Menunjukkan bahwa pada jarak $5 \mathrm{Km}$ dari reaktor G.A. Siwabessy merupakan daerah perencanaan tindakan yaitu daerah yang dalam melakukan tindakan penanggulangan dilakukan pengukuran terlebih dahulu pada daerah tersebut kemudian setelah didapatkan hasil maka dilakukan langkah tindakan penanggulangan. Tindakan yang dilakukan pada daerah tersebut meliputi sheltering, evakuasi, pemberian masker dan pemberian table iodine oleh organisasi penanggulangan kedaruratan nuklir tingkat propinsi. ${ }^{[8]}$

Menurut data rona lingkungan di wilayah Kawasan Nuklir Serpong (KNS) kecepatan angin rata-rata pada bulan Oktober-April (bulan basah) 3,6-5,2 $\mathrm{m} /$ detik dengan arah angin dari arah Selatan hingga Barat. Pada bulan Mei September (bulan kering) kecepatan angin rata-rata 2,1-5,2 m/detik arah angin dari Timur hingga Utara. Dengan demikian pada saat bulan basah pada jarak 35-50 Km dilakukan sampling udara pada daerah Timur sampai Utara dari reaktor G.A. Siwabessy dan dilakukan sampling udara pada daerah Selatan sampai Barat saat bulan kering pada jarak 25-50 $\mathrm{Km}$ untuk mengetahui radioaktivitas nuklida $\mathrm{I}-131$ pada daerah tersebut. 


\section{KESIMPULAN}

Dari hasil simulasi yang dilakukan untuk mengetahui besarnya radioaktivitas udara lepasan nuklida I131 pada saat terjadi kecelakaan reaktor RSG-GAS dengan postulasi 5 elemen bakar leleh dengan kondisi $60 \%$ udara permukaan kolam reaktor terhisap melalui sistem ventilasi dengan melalui filter dengan efisiensi (n) untuk iodine 0,99\%. Pada kecepatan angin $1 \mathrm{~m} /$ detik sampai dengan $5 \mathrm{~m} /$ detik radioaktivitas nuklida I-131 tertinggi pada jarak $0,5 \mathrm{Km}$ dari reaktor G.A Siwabessy yaitu 3,70E+05 $\mathrm{Bq} / \mathrm{cm}^{3}, 2,30 \mathrm{E}+05 \mathrm{~Bq} / \mathrm{cm}^{3}, 1,70 \mathrm{E}+05$ $\mathrm{Bq} / \mathrm{cm}^{3}, 1,30 \mathrm{E}+05 \mathrm{~Bq} / \mathrm{cm}^{3}$ dan $1,10 \mathrm{E}+05 \mathrm{~Bq} / \mathrm{cm}^{3}$. Daerah dengan radioaktivitas udara nuklida $\mathrm{I}-131$ mendekati nilai batas dari Bapeten untuk masing-masing kecepatan udara didapatkan jarak 15-50 Km dari reaktor G.A Siwabessy. Kecepatan angin 1 $\mathrm{m} /$ detik jarak $15 \mathrm{Km}$ radioaktivitas nuklida $\mathrm{I}-131 \quad 2,30 \mathrm{E}-02 \mathrm{~Bq} / \mathrm{cm}^{3}$, kecepatan angin $2 \mathrm{~m} /$ detik jarak $25 \mathrm{Km}$ radioaktivitas nuklida $\mathrm{I}-131$ 3,60E-2 $\mathrm{Bq} / \mathrm{cm}^{3}$, kecepatan angin $3 \mathrm{~m} /$ detik jarak $35 \mathrm{Km}$ radioaktivitas nuklida I$1313,30 \mathrm{E}-2 \mathrm{~Bq} / \mathrm{cm}^{3}$, kecepatan angin $4 \mathrm{~m} /$ detik jarak $45 \mathrm{Km}$ radioaktivitas nuklida l-131 2,60E-2 $\mathrm{Bq} / \mathrm{cm}^{3}$, kecepatan angin $5 \mathrm{~m} /$ detik jarak $50 \mathrm{Km}$ radioaktivitas nuklida $\mathrm{I}-131 \quad 5,40 \mathrm{E}-2$ $\mathrm{Bq} / \mathrm{cm}^{3}$ Sebaran radioaktivitas tersebut terdistribusi pada lokasi sesuai dengan datangnya angin.

Pada kecapatan angin $5 \mathrm{~m} /$ detik pada jarak di atas $10 \mathrm{~km}$ hasil perhitungannya besar karena faktor stabilitas udara pada input data yang digunakan stabilitas udara C (Slightly Unsable). Software Hotspot dalam manualnya memberikan informasi bahwa pada jarak lebih besar dari 10 $\mathrm{Km}$ hasil perhitungannya mempunyai akurasi yang kurang baik. Hasil perhitungan aktivitas yang dilakukan oleh peneliti[9] aktivitas lebih rendah bila dibandingkan dengan souce term hasil perhitungan pada kondisi reaktor BDBA sehingga hasil perhitungan radioaktivitas nuklida $\mathrm{I}-131$ akan lebih rendah.

Dengan demikian jarak yang dilakukan pengukuran radioaktivitas nuklida I-131 dengan jarak $15 \mathrm{~km}$ sampai dengan $50 \mathrm{~km}$ bila hasil pengukuran hasilnya lebih besar dari ketentuan dari Bapeten maka pada lokasi tersebut dilakukan tindakan berupa pemberian table iodine, penggunaan masker, sheltering atau tindaka evakuasi terhadap penduduk pada lokasi tersebut.

\section{DAFTAR PUSTAKA}

[1]. PRSG-BATAN 2016, Program Kesiapsiagaan Nuklir Fasilitas RSG-GAS

[2]. BATAN-PRSG 2011, Laporan Analisis Keselamatan RSG GAS Rev. 11.

[3]. PPIKSN-BATAN 2015, Pemutahiran Data Rona Lingkungan

[4]. National Atmospheric Release Advisory Center 2010, HotSpot User Guide Versi 3.0.3

[5]. BATAN-PPIKSN 2012, Program Kesiapsiagaan Nuklir Kawasan Nuklir Serpong, Revisi 3

[6]. Bapeten 2010, Perka Bapeten No. 1 Tahun 2010 Tentang Kesiapsiagaan dan Penanggulangan Kedaruratan Nuklir

[7]. BAPETEN, Perka BAPETEN No. 7 Tahun 2017 Tentang nilai batas radioaktivitas lingkungan

[8]. Peraturan pemerintah No. 54 Tahun 2012. Tentang Keselamatan dan Keamanan Nuklir 
[9]. Perhitungan lepasan bahanbahan radioaktif asal RSG-GAS di bawah keadaan kecelakaan (dengan asumsi 5 perangkat bakar meleleh) dan dampak radiologinya ke lingkungan.

Seminar Keselamatan Nuklir di Bapeten oleh Pudjijanto, MS dan Hudi Hastowo 